\title{
A Cross-organizational Ecology for Virtual Communities of Practice in Higher Education
}

\author{
Aekaterini Mavri, Andri Ioannou \& Fernando Loizides
}

To cite this article: Aekaterini Mavri, Andri loannou \& Fernando Loizides (2019): A Crossorganizational Ecology for Virtual Communities of Practice in Higher Education, International Journal of Human-Computer Interaction, DOI: 10.1080/10447318.2019.1664067

To link to this article: https://doi.org/10.1080/10447318.2019.1664067

册Published online: 16 Sep 2019.

Submit your article to this journal

Џ Article views: 24

Q View related articles $₫$

View Crossmark data \lceil 


\title{
A Cross-organizational Ecology for Virtual Communities of Practice in Higher Education
}

\author{
Aekaterini Mavri (1) ${ }^{\mathrm{a}}$, Andri loannou (10), and Fernando Loizides (1) ${ }^{\mathrm{b}}$

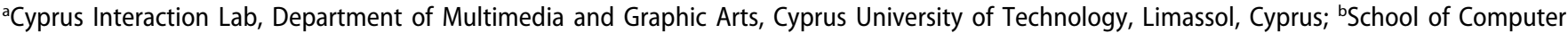 \\ Sciences \& Informatics, Cardiff University, Cardiff, UK
}

\begin{abstract}
This work investigates Communities of Practice (CoPs) that support social learning in higher education. While most CoP research has taken place in single-stream contexts (e.g. in a university), this study reports on the ecology of a cross-organizational community (university and industry stakeholders) in the context of the formal curriculum. The work examines the role of technology configurations in supporting CoPs in Design and related studies. It also reports on the type and level of technology adoption, focusing on the learner perspective. This study's CoP is made up of 21 third-year university students and ten external stakeholders (mentors, clients and industrial experts). The study concludes with a set of guidelines for the design and evaluation of similar CoP technology configurations. Key guidelines suggest a) supporting enhanced awareness of identity, space and time, b) enabling roles and permissions on-demand according to the requirements of the activities carried out in shared spaces and c) facilitating fluid interoperability between the domain-specific and mainstream/generic productivity tools used by the community. The outcomes of this work can assist instructors, researchers and practitioners in the design of similar technology configurations for CoPs in the formal curricula of their respective Design or relevant fields.
\end{abstract}

\section{Introduction}

The present study proposes an ecology to support and enhance the learning and outcomes of students in higher education (HE) through participation in cross-organizational Communities of Practice (CoPs).

CoPs are groups of people who share a common interest and goal in a specific area and collectively create and share knowledge and expertise through continuous social interaction with others (Wenger, McDermott, \& Snyder, 2002). The CoP framework, which originates from situated learning and cognitive apprenticeship theories (Brown, Collins, \& Duguid, 1989; Lave \& Wenger, 1991), sees the community as "a living curriculum for the apprentice" (Clarke, 2009) or novice learner, giving the latter the opportunity to participate, observe and imitate more competent members of the community. By crossorganizational, we refer to communities that span across spheres, such as education and industry (Albats, 2018; Iskanius \& Pohjola, 2016). Through this connection, formal education programs can be supported by industry professionals, while simultaneously being augmented by authenticity, by which we mean learning that is informed by real-world problems, needs and evaluation criteria (Bhatnagar \& BadkeSchaub, 2017).

The present study zooms in on a specific area that has been underexplored by the broader body of research on the design of virtual Communities of Practice (VCoPs) in HE (Khalid \& Strange, 2016; Rourke \& Mendelssohn, 2017; Wenger, White, \& Smith, 2009). This study looks at an ecology and technology configuration that is localized in HE Design and relevant disciplines, such as Engineering, Architecture, Technology and Human Computer Interaction (HCI). These disciplines share a number of characteristics: a) they largely take a social and situated approach, relying extensively on social infrastructure (team-based) and real-life contexts to support creative collaborations for the development of innovative products that serve a real-world purpose (Dym, Agogino, Eris, Frey, \& Leifer, 2005), b) they also tend to follow a user-centered design approach (UCD), requiring the systematic participation of various stakeholders (i.e. end-users, clients, experts) across multiple design and evaluation processes (communitycentered) (Lazar, Preece, Gasen, Winograd, \& Winograd, 2002) and c) to generate products, their technology needs tend to include code development tools (programming), visualization (brainstorming, mapping, diagramming), creativity-support (sketching, modeling, designing, animating), as well as communication activities (i.e. social networking, chat, conferencing) (Gabriel, Monticolo, Camargo, \& Bourgault, 2016; Nguyen, Dang, Do, \& Tran, 2016).

The study presents the design of an affordable technological configuration that can support the social learning processes of students in Design and relevant fields. To date,

CONTACT Aekaterini Mavri aekaterini.mavri@cut.ac.cy Cyprus Interaction Lab, Department of Multimedia and Graphic Arts, Cyprus University of Technology, 30 Archbishop Kyprianou Str. 3036, Limassol, Cyprus.

Color versions of one or more of the figures in the article can be found online at www.tandfonline.com/hihc.

(c) 2019 Taylor \& Francis Group, LLC 
CoP research has taken an intra-organizational approach, concentrating on either the academic or professional context (Crossouard \& Pryor, 2008; deChambeau, 2017; Stone et al., 2017). The investigation of the setup and impact on learning of cross-organizational CoPs that connect education and industry is still largely missing from literature.

There are multiple aspects of investigating such CoPs, e.g. their design (technological, organizational, instructional), their social learning processes and their epistemic outcomes. By epistemic we refer here to the outcomes that reflect knowledge and learning (Carvalho \& Goodyear, 2014). The perspectives from which to investigate these outcomes also vary, e.g. the students', the faculty's or the industrial stakeholders'. While they may all help illustrate a more complete picture of CoPs in HE, the scope of this research focuses on the aspect of technology in supporting both internal teamwork and external collaboration (industry). It also looks solely into the learner perspective, while the perspectives of other stakeholders are analyzed in separate work. In this study, the overarching questions are:

(1) How can a cross-organizational CoP technology configuration be designed to address the collaboration needs of $\mathrm{HE}$ learners in Design and relevant disciplines?

(2) How is the technological configuration adopted by the learners and what are the implications for the design of similar configurations?

The participants were third-year undergraduate students enrolled in a blended Design course (in-class and online) and industry agents who guided the students throughout the semester. Student teams were physically co-located, but frequently communicated and worked together online, while members from the industry participated remotely. This arrangement placed a crucial role on technology in supporting both intra (university) and inter (university-industry) activities, bypassing the restrictions caused by not sharing space and time.

In the following sections, we summarize similar work in the area and describe the study's ecology in terms of CoP structure and technology setup. We then carry out an analysis of qualitative findings and offer a set of guidelines for the design and evaluation of CoPs in similar domains.

\section{Related work}

\subsection{Communities of practice}

The theoretical framework of CoPs (Wenger, 1998) posits that three critical components are required to make a community: a) a joint enterprise (common purpose), b) mutual engagement (entwined participation) and c) a shared repertoire (vocabulary, resources and ways of conduct tacitly developed over time). CoPs allow for Legitimate Peripheral Participation (LPP) (Lave \& Wenger, 1999), that is the entry and gradual progress of newcomers in a community by means of observing, mimicking and learning from more experienced others, through a desired degree of participation (Eggleton, Fortier,
Fishman, Hawken, \& Goodyear-Smith, 2019). With LPP, newcomers go through a journey of enculturation and gradually move toward greater levels of knowledge and competency (Boylan, 2010).

This study builds on the existing body of research that has looked at the positive role of CoPs in social learning and knowledge networks (McLoughlin, Patel, O'Callaghan, \& Reeves, 2018; Tseng \& Kuo, 2014), driving innovative thinking (Stone et al., 2017) and assisting in professional development (Brown, 2015; Khalid \& Strange, 2016) in both educational (deChambeau, 2017) and industrial settings (Hafeez, Alghatas, Foroudi, Nguyen, \& Gupta, 2019; Huang \& Perng, 2017; Pattinson \& Preece, 2014).

\subsubsection{Technology-supported communities}

Wenger's framework (Wenger et al., 2009) for virtual Communities of Practice (VCoPs) (Hafeez et al., 2019) asserts that technology comprises four components: tools, features, platforms and configurations: a) tools: software for specific purposes (i.e. an email client) (Cherry \& Latulipe, 2014); b) platforms: packages that combine tools (Spagnoletti, Resca, \& Lee, 2015) like for instance Google's G Suite ("G Suite: Collaboration \& Productivity Apps for Business,” n.d.), used for communication, productivity and storage, with common access and functionality; c) features: specific properties supported by the user interface (i.e. filtering, sorting); and $d$ ) configuration: the entire arrangement of the abovementioned platforms and tools. A course could employ, for instance, a Learning Management System (LMS), supported by a social network (SN) (deChambeau, 2017; Gunawardena et al., 2009), as well as domain-specific software, like a Creativity Support Tool (CST) to accommodate the specific needs of a domain (Cherry \& Latulipe, 2014). For the purposes of this work, CSTs refer to software for the development of creative artifacts e.g. a written article or a design item.

The theory (Wenger et al., 2009) further proposes nine major categories of activities or 'orientations' in VCoPs: meetings, open-ended conversations, projects, content, access to expertise, relationships, individual participation, community cultivation, and servicing a context. Orientations are useful if mapped against field-specific (i.e. software development) activities (see Table 1) as they can directly translate into technical requirements for the community setup.

It is important to note that while fundamental to VCoPs, technology configurations alone do not constitute a recipe for success (Smith, Hayes, \& Shea, 2017; Wenger et al., 2009). Their key purpose is to serve the unique requirements and characteristics of the field of practice and support the specific CoP infrastructure in which they are deployed (Smith et al., 2017).

In this study, the CoP extends across education and industry; hence, its configuration must consider the respective characteristics and constraints of each sphere, as well as those that emerge at their intersection (Albats, 2018). Technology's role in mediating real-world relevance (Bhatnagar \& Badke-Schaub, 2017) is critical, as it can proactively induct novices into professional practice (Brown, 2015; Herrington, Reeves, \& Oliver, 2014). This perspective should be noted especially nowadays, when industryuniversity alliances are increasingly endorsed by academic 
Table 1. CoP steward's orientations and activities mapped from the WDD process model.

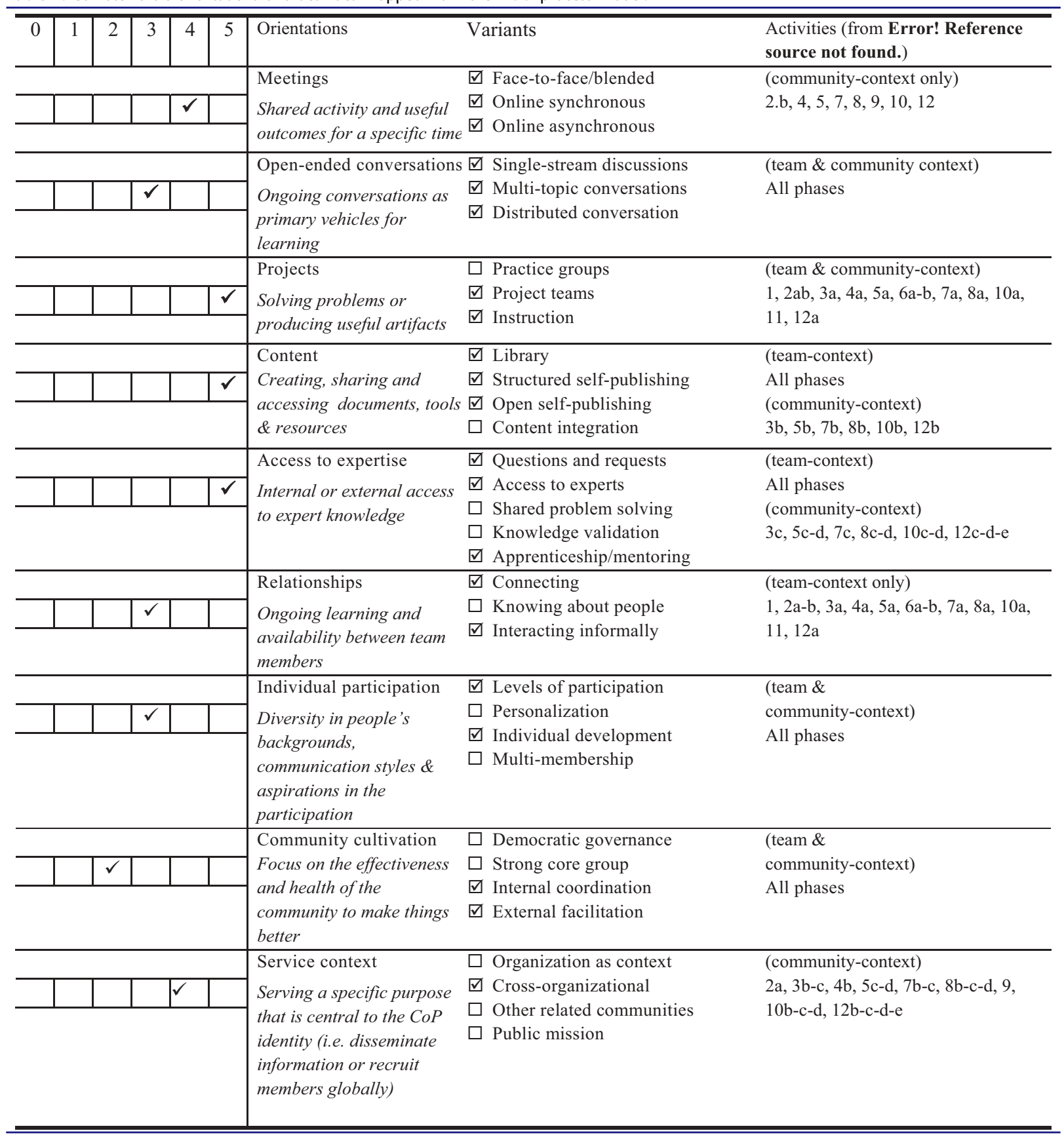

institutions (Iskanius \& Pohjola, 2016; Mulgan, Townsley, \& Price, 2016). That said, only a few VCoP studies have chosen to consider cross-organizational setups. This may be due to the complexity of investigating multi-level communities that comprise heterogeneous agents (Albats, 2018).

Some studies have taken an interim step by investigating CoPs across disciplines or institutions, but staying within the same sphere (i.e. universities) (Jeffs et al., 2016; Pattinson \& Preece, 2014; Pharo, Davison, McGregor, Warr, \& Brown, 2014). Others have focused on the semantic constituents of a domain (i.e. design studios as a precursor to a professional practice) in preparing learners to transition into the industry
(Morton, 2012). However, this approach may not be sufficient in realizing the full extent of LPP that real-world contexts can supply. Going a step further, some studies investigated the benefits and limitations of CoPs in student work-placement schemes (Johnston, 2016). Brown's (2015) study for instance, focused on the benefit felt by interns due to their participation in a CoP physically situated in a professional setting. Observing job supervisors (the experts in the community) facilitated good informal LPP for the interns, strengthening their reflection skills. Yet, compared to on-location placement, a technology-enabled cross-organizational CoP in $\mathrm{HE}$, has two advantages: a) it allows for collaboration, while 
filtering out the irrelevant information, delays and risks that occur in real-life practice, which serve no benefit to novices, and b) it allows students to prepare for the important demands and challenges of the industry, by providing a solid perspective of the professional field as part of the formal curriculum (Brown, 2015; Herrington et al., 2014).

Hence, we believe there is a need to give due attention to: a) specialized CoPs that address the particular "epistemic and discursive practices" (Smith et al., 2017) situated in the challenges and dynamics of the field, as opposed to a "one fits all" model (Hafeez et al., 2019; Huang \& Perng, 2017; Pharo et al., 2014; Smith et al., 2017) and b) CoPs, from which HE learners can benefit by transcending organizational barriers and gaining authentic knowledge and experience of real-world practices (Albats, 2018; Brown, 2015; Johnston, 2016; Lombardi, 2007).

\section{Methodology: the ecology}

\subsection{Research design}

The present work is part of a larger investigation of crossorganizational CoPs in HE, and follows a mixed method research design to utilize the advantages of both quantitative and qualitative research data and findings (Norman, 1986). It focuses primarily on a CoP's technology configuration - the digital setup - and how this was adopted by the student-members of the CoP.

\subsection{Participants}

The 21 students who participated in this study enrolled in a semester-long Web Design and Development (WDD) course employing a UCD approach. Students self-formed mixed-gender teams of four (5 teams x 4 students). Such teams or subgroups working toward the development of artifacts, are common in CoPs, with knowledge building, deliverables and the dissemination of outcomes, seen as the contributions back to the community (Wenger et al., 2009).

\subsection{Learning setting}

The WDD module, guided by UCD methods and relevant processes (see Table 1), focuses on building basic knowledge around front-end web technologies, such as HTML, CSS and JavaScript. The course (180-minute lessons x 13 weeks) ran for three months over the course of the first semester of the academic year. The typical epistemic activities were research, ideation, documentation, diagramming/charting, visual prototyping (Shneiderman, 2000), GUI (graphical user interface) design and coding. A full classification of activities and processes can be found in Table 2. These were partially derived from discussions with students; after an initial walk-through of the action plan, teams talked informally about their prospective orientations with the instructor. The classification of activities was also informed by related theoretical sources, as well as the instructor's prior teaching knowledge and industry experience in the field.

\subsubsection{In-class learning}

A problem-based-learning (PBL) approach (Savery, 2015) was employed in class, where students were given ill-structured, 'messy' problems to solve (Dolmans, Michaelsen, Van Merrienboer, \& van der Vleuten, 2015; Duch, Groh, \& Allen, 2001). A large part of the lab-based collaborative activities were performed using online tools; these helped address the lack of team workspace that is typically experienced in computer labs (i.e. flat spaces or large screens that facilitate team research, brainstorming or visual experimentation). The used of collaborative real-time online tools also helped limit the degree of noise that is often generated by large groups.

Table 2. WDD process model based on WDD (Lowe \& Eklund, 2002) \& UCD (Vredenburg et al., 2002).

\begin{tabular}{|c|c|c|}
\hline \multicolumn{3}{|c|}{ Web Design \& Development (WDD) process model: phases and activities } \\
\hline 1. Project planning & a. & $\begin{array}{l}\text { Research \& documentation } \\
\text { (subject and users) }\end{array}$ \\
\hline 2. Requirements & $\begin{array}{l}\text { a. } \\
\text { b. }\end{array}$ & $\begin{array}{l}\text { Gathering } \\
\text { Analysis \& documentation }\end{array}$ \\
\hline 3. Project charter/proposal & $\begin{array}{l}\text { a. } \\
\text { b. } \\
\text { c. }\end{array}$ & $\begin{array}{l}\text { Author \& document } \\
\text { Publish online } \\
\text { Client feedback }\end{array}$ \\
\hline 4. Content & $\begin{array}{l}\text { a. } \\
\text { b. } \\
\text { c. }\end{array}$ & $\begin{array}{l}\text { Define needs \& document } \\
\text { Provisions/exchange/delivery } \\
\text { Store \& share }\end{array}$ \\
\hline 5. Sitemaps & $\begin{array}{l}\text { a. } \\
\text { b. } \\
\text { c. } \\
\text { d. }\end{array}$ & $\begin{array}{l}\text { Create \& document } \\
\text { Showcase online } \\
\text { Client feedback } \\
\text { Informal expert evaluation }\end{array}$ \\
\hline 6. Work breakdown structure & $\begin{array}{l}\text { a. } \\
\text { b. }\end{array}$ & $\begin{array}{l}\text { Card sorting } \\
\text { Create \& document }\end{array}$ \\
\hline 7. Time-planning & & $\begin{array}{l}\text { Create \& document } \\
\text { Publish online } \\
\text { Client feedback }\end{array}$ \\
\hline $\begin{array}{l}\text { 8. Ideation and visualization: wireframes \& } \\
\text { annotations (low fidelity) }\end{array}$ & & $\begin{array}{l}\text { Iterative design \& } \\
\text { documentation } \\
\text { Online showcase } \\
\text { Client feedback } \\
\text { Informal expert evaluation \& } \\
\text { feedback }\end{array}$ \\
\hline
\end{tabular}

9. User testing, role-playing and walkthroughs

10. High fidelity prototype development
a. Iterative design \& documentation
b. Showcase online
c. Client feedback
d. Informal expert evaluation \& feedback

11. Heuristic evaluation

12. Development

\author{
a. UI development \\ b. Publish online \\ c. Client feedback \\ d. Informal expert evaluation \& \\ feedback \\ e. Formal expert evaluation
}




\subsubsection{Out-of-class learning}

The student teams $(\mathrm{N}=5)$ were assigned different real-life projects, based on the needs of a corresponding number of local businesses. While the topics varied for each team, they all had to produce the same deliverable, i.e. a website.

\subsection{The CoP}

Soon after the course started, the student focus groups confirmed that an organic student community had naturally formed. With varying levels of knowledge, students helped each other on WDD topics in face-to-face exchanges, both in and outside class. Students also made use of a Facebook group-chat that they had set up in the first year of their studies; the group was used for posting announcements and other general information for resource sharing and for providing mutual support.

The study employed an authentic CoP model (Iskanius \& Pohjola, 2016), with members from the industry willingly joining the community as mentors and expert evaluators for the students. These members tend to be ethically motivated to share their expertise and contribute positively to higher education. Additionally, joining the CoP was also perceived as an opportunity to have a voice in education and hence help shape prospective graduates as the human capital transitioning into the local industry.

In this manner, the community came to comprise both academic and industrial members. Members included: a) an instructor b) a floating facilitator, i.e. a final year teaching assistant who supported team discussions and provided technical advice and general guidance, c) alumni mentors, i.e. three alumni students with at least two years of industry experience in the field, who offered regular feedback at project milestones, d) industrial experts, i.e. three professionals with a minimum of six years of experience in the field, who were responsible for the evaluation and feedback on student work, and finally e) industrial mentors (clients), i.e. five companies operating in the fields of law, finance, property development, sports management and the non-profit sector.

\subsection{The digital setup}

Wenger White and Smith (Wenger et al., 2009) proposed three key steps for CoP technology design and administration, presented in Table 3. The following sections analyze and explain how the first two were adopted within the scope of this study, which focuses on a VCoP. The third step, which is dependent on outcomes from the first two, warrants more exhaustive analysis and is fully covered in parallel work.

Step 1: mapping community orientations to the study's process model. Orientations are the basis from which to start thinking about the technology serving the CoP needs. According to the framework's guidelines, if the community is not yet fully formed, the tech steward (the instructor, in this study) can use these orientations to instigate discussion, either with the entire $\mathrm{CoP}$ or a small group within it (students, in this study), to prompt them to formulate their practice needs.
Table 3. Action for the design and stewarding of CoPs.

Stewarding technology steps for digital CoPs (VCoPs) (Wenger et al., 2009)

- Step1: understanding the community, its characteristics, orientation, and current configuration.

- Step2: providing technology, choosing a strategy, selecting a solution, and planning the change.

- Step3: stewarding technology in use, in the life of the community and at its closing.

The CoP tech steward can then "create an intended community profile in terms of orientations and their variants" (Wenger, 1998).

The primary aim of the technology was to facilitate collaborative practices among the CoP learners. These practices emerged via informal discussion with students, as mentioned earlier. Additionally, theory-derived subjectspecific activities were considered. Since this was a WDD course following a UCD methodology, we borrowed from both WDD and UCD literature to choose the appropriate index of activities, as described in the following two sections.

User centered design (UCD). UCD is a science (Norman, 1986) that incorporates the user's targets, needs and limitations as a primary dimension of the design process from project initiation to completion (Baek, Cagiltay, Boling, \& Frick, 2008). Most UCD methods are employed in the course of design and development to elicit basic information about the user and the product (i.e. a system) and then draw usability conclusions by means of techniques such as questionnaires, interviews, field observations, eye tracking, and software logs (errors, completion times) (Abras, MaloneyKrichmar, \& Preece, 2004; Lowdermilk, 2013; Vredenburg, Mao, Smith, \& Carey, 2002). For the purposes of this study, we adopted the process model by Vredenburg et al. (Vredenburg et al., 2002), which includes key UCD phases and activities (see Table 2).

Web Design and Development (WDD). This comprises conceptual, presentational, navigational and structural aspects of design (Conte, Massollar, Mendes, \& Travassos, 2007). On a practical level, it includes: a) the translation of business and end-user needs into the design requirements, b) page layout and GUI design, c) web development and d) system architecture design. We draw from Low and Eklund's (Lowe \& Eklund, 2002) WDD process typology to inform the model for this study. We outline an adaptation of the combined WDD and UCD process models in Table 2. As recommended by the CoP framework, this table was laid out to match our WDD process model against community orientations (Wenger et al., 2009).

Step 2: Technology acquisition strategy. Communities are driven by various factors when choosing their technology, such as what is commercially available or what is enforced by an organization, for instance, specific business software (Wenger et al., 2009). In this study, the university-based members of the community had already been actively using free tools, such as Facebook and Google Drive, but extending 
these to external stakeholders presented limitations and warranted new technology decisions. Proprietary community software or platforms were not an option, as the diversity in the members' technical literacy skills, as well as logistical and cultural characteristics, were prohibitive. Additionally, no platform offered a full suite of the tools and features (i.e. the digital creative tools) that the community required for both generic and subject-specific activities. Technology acquisition strategy was thus developed based on a) ease, availability and affordability (i.e. either free or low-cost, e.g. monthly subscription-based tools), b) the efficiency of the tools in facilitating shared visual design functionality and c) their similarity to applications with which the community was already familiar.

Step2a: Technology configuration. A proposed technology inventory presenting the various platforms, tools, features, supported activities, context and deliverables can be seen in Table 4. These are classified in 'team', 'community' and 'single-user' contexts, as follows:

\section{Team context}

- Google Drive \& Google Docs ("Google Drive - Cloud Storage \& File Backup for Photos, Docs \& More,” n.d.): for document creation, management and sharing.

- ConceptBoard ("Conceptboard - Virtual Collaboration Workplace for Teams," n.d.): a shared digital whiteboard with direct manipulation and synchronous/asynchronous communication facilities such as live chat, stickies, video-conferencing and screen-sharing (see Figure 1).

- Adobe Dreamweaver (Version 12, 2012) (Adobe Dreamweaver, 2012): a web development tool (code/ WISWIG editors) and built-in File Transfer Protocol (FTP) for publishing websites.

\section{Community context}

- Behance ("Behance," n.d.): an online visual workpromotion platform, allowing media uploads and posts in an integrated forum (see Figure 1).

- Hypothes.is ("Hypothesis - The Internet, peer reviewed.," n.d.): a browser-based, real-time annotation feedback tool (see Figure 1)

- Moodle ("Moodle - Open-source learning platform | Moodle.org," n.d.): an LMS for course material (lesson plans, lecture notes and assignments).

\section{Single-user context}

- Axure RP (Version 8.1, 2017) ("Prototypes, Specifications, and Diagrams in One Tool | Axure Software," n.d.): for rapid prototyping (wireframes and interactive proof-ofconcepts).

- Adobe Photoshop (Adobe Photoshop, Version 13, 2017) ("Buy Adobe Photoshop CC | Best photo, image, and design editing software," n.d.): a desktop raster graphics editor for digital photo manipulation.

- Adobe Illustrator (Adobe Illustrator, Version 8.1, 2017) ("Buy Adobe Illustrator CC | Vector graphic design software," n.d.): a desktop vector graphics editor for digital typesetting, graphic design and illustration.

\section{Data collection and analysis}

The study collected qualitative data from student focus groups, which took place between weeks 4 and 13 (5 teams x 3 sessions); important perceptions and incidents were thus captured retrospectively, but while still fresh in the students' minds. The focus groups were typically held after class in the university labs, with the project teams and one researcher who acted as the moderator. Guided by a set of questions, students expressed their views on the technology configuration. As a "pre-existing group" (Bloor, 2001) they were familiar with each other and felt comfortable speaking freely in the presence of other team members. The sessions were recorded, resulting in a total of 7,5 hours (with a mean duration of 37 minutes per session) of collected data.

\subsection{Technology adoption}

The term 'technology adoption' is most frequently associated with technology acceptance frameworks, with TAM (Technology Adoption Model) (Davis, Bagozzi, \& Warshaw, 1989), being the most widespread. TAM has been validated and extended through multiple studies in diverse fields (Rauniar, Rawski, Yang, \& Johnson, 2014; Renaud \& Van Biljon, 2008; Venkatesh, Morris, Davis, \& Davis, 2003). This model is typically used for forecasting technology use, using intention as the dependent variable. A psychometric instrument measures technology acceptance via a set of variables, such as Perceived Usefulness and Perceived Ease of Use.

In contrast, the purpose of this study was to gain a wellrounded view of the participants' experience retrospectively. We aimed to gather rich information and uncover unanticipated phenomena that may have emerged from the specific blending of a cross-organizational CoP's practice with a technology configuration and the field of Design and related disciplines (a new and targeted niche). We therefore judged that a fully qualitative approach, flexible enough to allow for the emergence of new information, was more appropriate to gain a better understanding of the convergence of the three areas (Maxwell, 2012).

We employed inductive thematic analysis (Chi, 1997; Patton, 1980) for the qualitative data collected from the focus groups to investigate how technology facilitated or hindered participation in the CoP. We looked exclusively at the learner perspective, and tailored our research questions accordingly. We used a fully qualitative reflexive approach (Braun, Clarke, Hayfield, \& Terry, 2019) and presented the emergent coding scheme as an outcome of this process (versus a priori codebook for the analysis) (Saldaña, 2015).

In summary, the complete dataset underwent a preliminary scan and only relevant subsets concerning the role of technology were coded. Each team was defined as a case of analysis and complete argument chains (multi-sentence segments) were defined as a unit of analysis. This was due to the researchers being limited to extracting semantically inclusive 


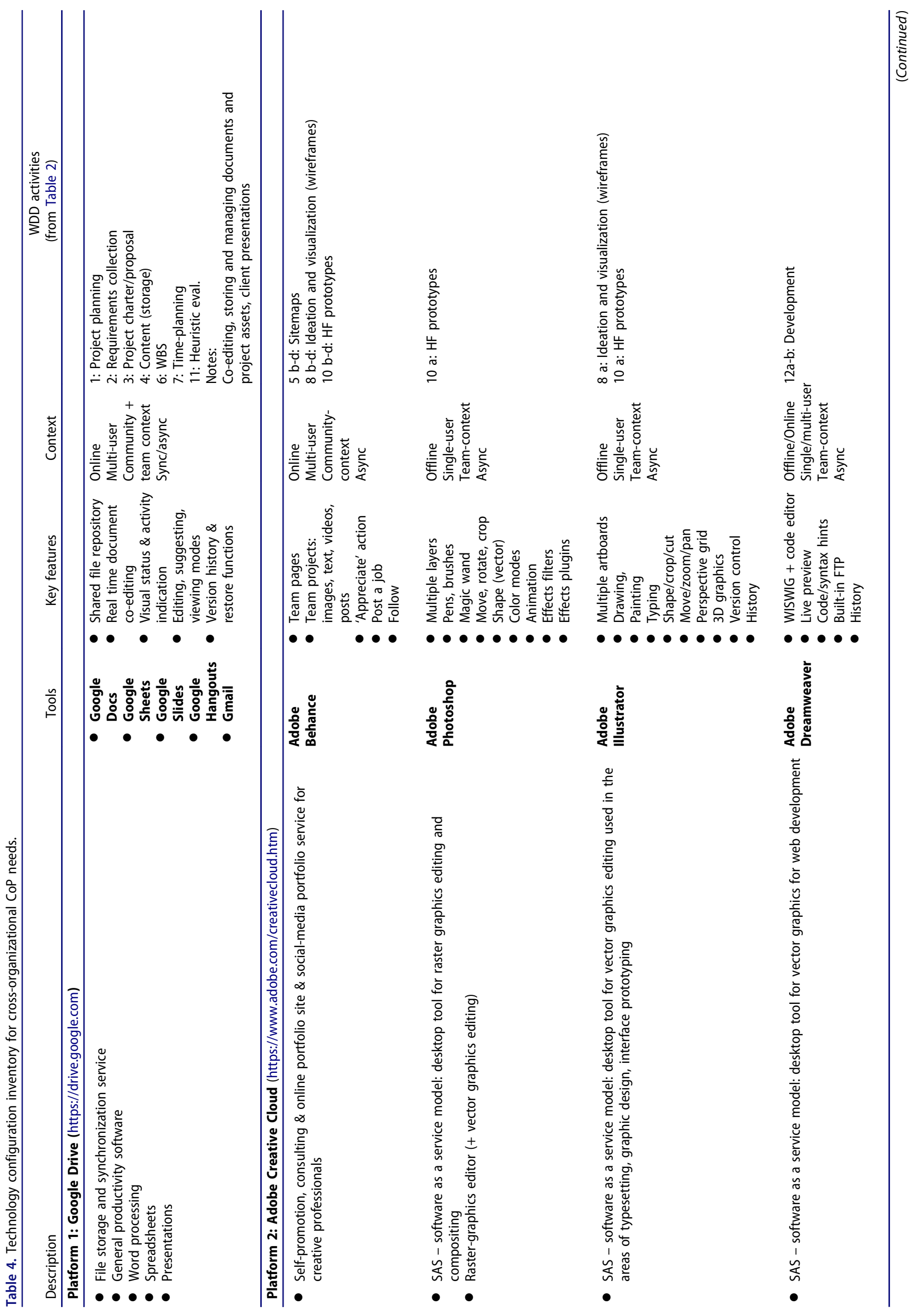




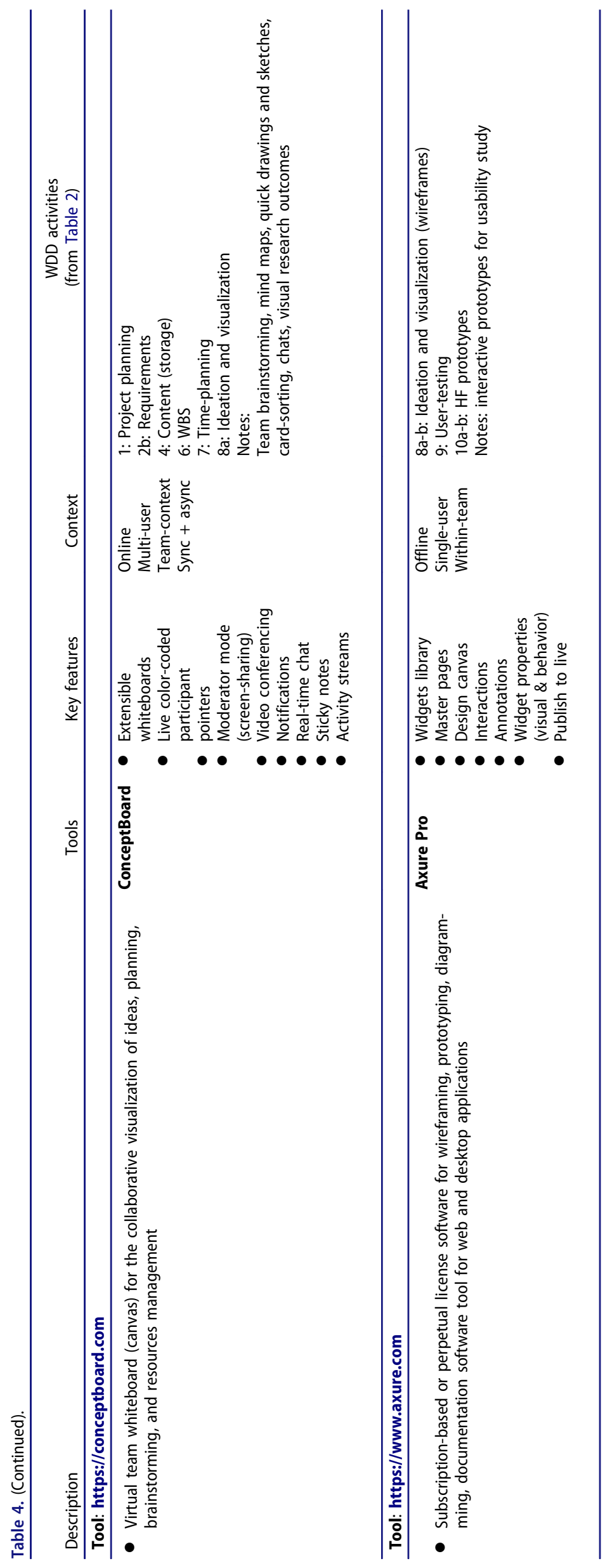



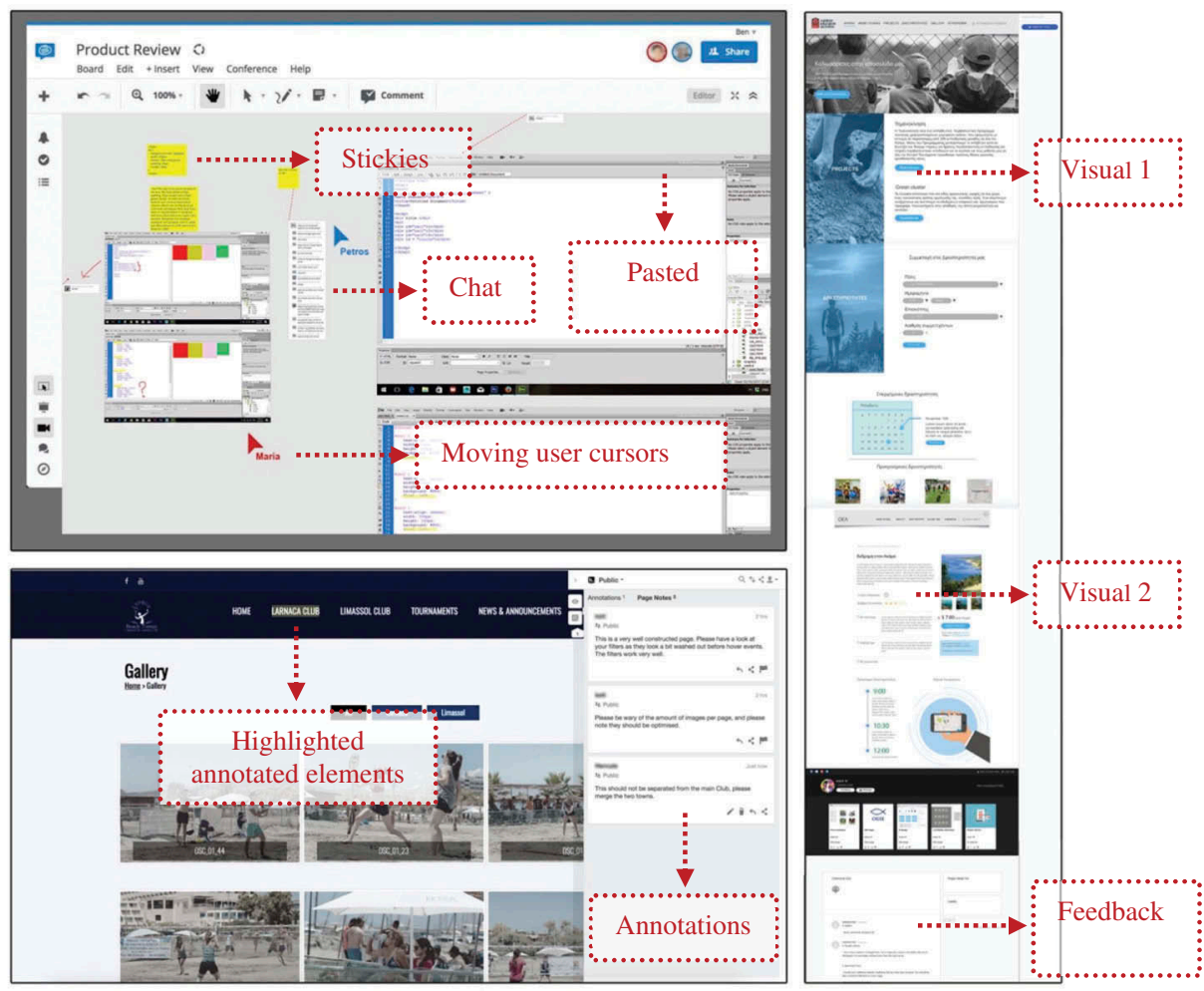

Figure 1. Conceptboard (top-left), Hypothes.is (bottom-left) and Behance (right) screenshots.

inferences from finer-grained segments (i.e. single-line utterances) to inform the research objectives.

Next, a coding scheme reflecting a) the meaning of data and $b$ ) important theoretical variables of "the current domain" (Chi, 1997) was used for coding the selected subsets (see Table 5). In other words, while the codes and categories were derived from the data, some of these were found to closely reflect variables of $\mathrm{CoP}$ theory and were therefore titled accordingly. Specifically, certain codes and categories aligned with typical community challenges, otherwise known as polarities: a) rhythm: togetherness and separation (time and space), b) interaction: participation \& reification (co-construction of artifacts) and c) identity: individual (see Table 5).

Simultaneous coding was applied (coding text in more than one code) to capture critical data perspectives (Saldaña, 2015). It was important for the researchers to document the multidimensionality of each inference as these could, for example, refer to definitive properties, such as a synchronous/asynchronous, team-only or community-wide activity that occurred in a certain tool and generated specific findings. Finally, a total of 7 categories and 382 code references were recorded (see Table 5). The most prominent categories and their inter-relationships are reported below, grouped by the software tools used in the study.

\subsubsection{Conceptboard}

The participants considered this tool to have adequately facilitated team communication and coordination activities through voice and video conferencing, screen-sharing and chat. The system's synchronous (live editing, video/voice) and asynchronous (i.e. sticky notes on elements, chat history) affordances were extensively used. Further, the large canvas and direct manipulation capabilities (pan, zoom in/out) effectively supported the kinds of experimentation required during the ideation phases: teams particularly favored the ability to use natural gestures in "throwing and moving things" around, dropping resources on the canvas, and using it as a mood-board, a brainstorming environment, or a card-sorting board.

That said, some participants reported issues of awareness. Apart from team $\mathrm{C}$ who remarked that "watching everyone's cursors move around" on the canvas was helpful (see Figure 1), the rest stated that they were unaware of their peers' concurrent activities in the environment. In fact, members from teams B and D went as far to say that their teammates acted quite individualistically and didn't respect their peers' activities in the shared space. Similarly, awareness issues around space and time also surfaced. Participants reported not knowing what the most recent creations or edits on the canvas were:

Team B member: It felt like a maze, because when someone inserted something somewhere in that chaos ... there were a lot of things everywhere but you couldn't know what the most recent action was ... to know what to do next.

Issues of ownership, like a lack of "safekeeping", thus became prominent. The ability to move or change artifacts on the canvas interfered with individual workflows and was perceived as intrusive and hence, counter-productive. Concurrent editing often led to overwrites and caused discord amongst teams: 
Table 5. Qualitative coding scheme for technology-related subsets from focus group data.

\begin{tabular}{|c|c|c|c|}
\hline Categories & Description & No. of codes & $\begin{array}{l}\text { No. of } \\
\text { references }\end{array}$ \\
\hline Software/platform & $\begin{array}{l}\text { Reference to the tools most often used by the CoP, whether core (obligatory) or } \\
\text { supplementary (optional) }\end{array}$ & 12 & 48 \\
\hline $\begin{array}{l}\text { Usability/affordances } \\
\text { (Norman, 1999) }\end{array}$ & $\begin{array}{l}\text { Reference to issues relating to the affordances of the system (issues of awareness, } \\
\text { concurrent viewing, perceptions of credibility and security) }\end{array}$ & 19 & 46 \\
\hline $\begin{array}{l}\text { Interaction features } \\
\text { (Wenger et al., 2009) }\end{array}$ & $\begin{array}{l}\text { Reference to the specific functionality facilitated by the software (video conferencing, } \\
\text { alerts, file sharing, direct manipulation) }\end{array}$ & 14 & 77 \\
\hline $\begin{array}{l}\text { Identity } \\
\text { (Wenger et al., 2009) }\end{array}$ & Reference to community-wide, team-based and individual activity & 3 & 44 \\
\hline $\begin{array}{l}\text { Rhythm: space } \\
\text { (Wenger et al., 2009) }\end{array}$ & Reference to online, offline or other (i.e. online co-located) activity & 3 & 44 \\
\hline $\begin{array}{l}\text { Rhythm: time } \\
\text { (Wenger et al., 2009) }\end{array}$ & Reference to synchronous or asynchronous interactions & 3 & 47 \\
\hline Attitude & Reference to positive, negative or neutral attitude & 3 & 76 \\
\hline
\end{tabular}

Team D member: Basically you can edit a piece of text $\ldots$ on one of the stickies and then you press enter to save it and it disappears all together! [someone else deleted it in the meantime].

\subsubsection{Adobe Behance}

Behance was used for uploading deliverables to be accessed by the wider CoP, so that members could view and post feedback via comments at the bottom of each page. Teams were prompted to create team accounts and organize each deliverable phase into a different project (a page with multiple visuals). Students found uploading and organizing quite practical: the tool's affordances were good for online showcasing (see Table 2 - sections 3,5,8,10). However, its role in facilitating feedback was problematic. The grouping of various visuals (i.e. home page, list-view, details template, etc.) generated long scrolling pages. Consequently, the comments were not physically close to the corresponding visuals. The tool's inability to put these in proximity, forcing users to scroll back and forth when trying to put together visuals and feedback, was perceived as hindering team flow.

More difficulties were reported on the limited amount of characters (a maximum of 125) allowed in feedback posts. This resulted in comments split across consecutive posts, creating a frustrating and fragmented experience. The lack of rich-text-box functionality, i.e. no formatting options, which would help indicate hierarchy or emphasis (for instance bold, underline and bullet points) in the comments, was also negatively received by the teams, who commented that the basic text format hindered the nuanced meaning of communications from coming across.

\subsubsection{Adobe Dreamweaver/FTP}

Dreamweaver CS6 (DRW) was used to transform the visual prototypes into functional web pages; these were then uploaded to a server via an FTP tool (see Table 4). DRW does not offer a synchronous multi-user editing facility. In terms of team collaboration, it offers partial version control through SVN (Apache Subversion), an open-source version control system (Wikipedia contributors, 2018). Based on its complexity and other testimonials that had reported issues, this pairing (DRW \& SVN) was not considered a suitable option for beginner-level students, especially given that they were already dealing with a considerable load: learning how to code and use new software, understanding the server environment and managing external CoP stakeholders. Teams had to therefore work on shared files sequentially, rather than concurrently, using DRW's file 'check-out'/'checkin' functionality. Yet, as the projects progressed, deadlines and other pressures eventually imposed the need for concurrent file editing. For instance, the main stylesheet file (CSS) (with site-wide formatting, layout and behavior specs) was often required simultaneously by different team members. In doing so, some participants reported feeling confused, having to manually track and merge different user changes. As expected, this led to overwriting, delays and frustration:

Team C member: They re-uploaded the file and it was spoiling others peoples' stuff.

The software's affordances in this case failed to support effective asynchronous collaboration, and resulted in more effort and time pressure on the novice learner teams.

4.1.4. Google Drive, docs, sheets, hangouts. Google Drive, Docs and Sheets were used for important weekly deliverables throughout the project phases, while Google Hangouts was minimally used for communication. Google Drive served as a primary repository for shared resource storage and document management. Interestingly, some teams reported that the tool could be enhanced if configured or used in conjunction with other software. For instance, team $\mathrm{C}$ members used it extensively alongside Conceptboard for collaborative exploration and experimentation. Nevertheless, specific areas within shared documents were designated by team members as 'private', in an effort to safeguard individual work and prevent problems similar to those faced in Conceptboard:

Team C member: We used it at the beginning ... to make a list of our own opinions ... but each of us had their own parts allocated in that document.

Likewise, team B further suggested that the process of feedback from the community could be better streamlined by pairing Google Docs and Behance in the future. With the use of cross-referencing to keep track, they proposed linking prototypes (Behance) to full feedback reports (Google Docs) to enhance their workflow. This could resolve the aforementioned issues of concurrent work/feedback, as well as the lack of rich-text-box functionality to format text in order to indicate semantics, while additionally allowing for effective 
documentation and searching activities. This arrangement requires targeted interoperability, which is to date not natively supported by these tools.

4.1.5. Hypothes.is. This tool, directly embedded on page elements in the form of annotations (see Table 4), was used by mentors and clients to post feedback on the webpages. This type of feedback was submitted over the final two weeks of the semester. The tool was well-received as immediate, efficient and thus highly practical for this purpose:

Team B member: Instead of sending the code and having to indicate the line, this is a much nicer tool!

As Hypothes.is only offers two annotation modes: "public" and "only $m e$ ", some skepticism regarding the veracity of written feedback was expressed, as anyone could submit a comment. According to participants, additional ownerdefined (customized) "view \& edit" modes, could extend user privileges and better target activities suitable for either within-team or CoP-wide contexts.

4.1.6. Adobe illustrator/Adobe Photoshop. These single-user CSTs were used to develop low and high-fidelity prototypes (see Table 2 , sections 8,10 ). The vast majority of participants agreed against the synchronous co-design and editing of such artifacts. According to multiple participant views, such stages of intuitive, creative and refined design work dictated a highly individual, independent, unstructured and unmonitored process:

Team A member: When you are artist ... You cannot do that ... artistic activity cannot be collaborative in real time, like working on a common design.

While collaboration was welcomed and in fact, perceived as necessary during the earlier brainstorming, analysis, critiquing and orientation stages (Poole \& Holmes, 1995), the creative development phases that came next required a more definitive division of roles. These tools were thus used by participants as intended, i.e. in a non-collaborative way.

\section{Discussion}

The objective of this work was to describe a cross-organizational $\mathrm{CoP}$ technology configuration localized to the learning requirements of an HE course in the field of Design and related disciplines (i.e. Architecture, Engineering, HCI). Such disciplines share certain perspectives, for example, they rely on the creative collaboration of teams whose purpose is to produce novel products for the real world. In doing so they require a blend of technologies for technical development, visualizations, creative design and communication, and are largely user-driven, thus requiring the participation of several members from each community. In investigating and describing the design of an ecology that can support these perspectives, the study examined the type and degree of technology adoption by the students that participated in the CoP.

To address how this CoP model can be supported through technology given the particular needs of the design disciplines in HE (RQ1), this work drew on the VCoP framework guidelines (see Table 3) by Wenger, White and Smith (Wenger et al., 2009). In particular, the configuration strategy for the digital setup of the CoP was guided by the following criteria to: a) to maintain similar tools similar to those already used in the community b) to avoid complications associated with the use of proprietary software due to the dispersion of stakeholders in the cross-organizational community (technology limitations, permission policies, cultural characteristics, technical literacy) and c) to use free or affordable web-based technologies that could be easily and flexibly adopted by all $\mathrm{CoP}$ members, as well as transferrable beyond university settings, enabling the possible perpetuation of the community. The intended technology configuration comprised tools relating to productivity (Google Drive, Google Docs), communication and networking (email clients, Facebook Groups, chat), creativity-support (Adobe Suite, ConceptBoard, Axure) and embedded feedback (Hypothes.is), as well as online portfolio platforms (Behance) and learning management systems (Moodle).

Through a technology adoption analysis (RQ2) the study found that user awareness of identity (other users \& roles), space (virtual position) and time (when activities occurred) is critical to ensure efficient subgroup (team) collaboration, particularly in using synchronous visual CSTs. From a CoP-wide perspective, virtual spaces should facilitate various embedded media channels (audio/video conferencing, chat, screen sharing etc.), multiple user roles and activity privileges and most importantly, interoperability with popular services such as SNs, so as to access common data and functionality without the deployment of multiple software tools.

Based on the above, we propose a set of guidelines for instructional designers or instructors looking to design or evaluate $\mathrm{CoP}$ technology configurations in HE Design studies or related fields.

\subsection{G1. Enhance workspace awareness: identity, position and activity}

Lack of suitable application affordances led to insufficient workspace awareness (Gutwin, Greenberg, \& Roseman, 1996), particularly in the case of synchronous CSTs (Conceptboard), where space and time-related issues were reported. Duplicate actions, overwrites and resultant misinterpreted social behaviors (i.e. lack of accountability) were also reported (Forghani, Venolia, \& Inkpen, 2014). This accentuated feelings of ownership and individuality, rather than collegiality and collaboration. Users of visual CSTs need to be truly 'immersed' in the virtual space (Cherry \& Latulipe, 2014). Hence the interface should naturally allow for awareness without added overhead, like for instance having to shift attention between panels or windows to detect peer activity. Instead, the latter should be intuitively perceived, as in real life, also known as "lightweight information gathering" (Gutwin et al., 1996). Simple means of awareness enhancement could be employed. Based on participant suggestions, concurrent peer activities could be communicated through userdefined color-coding (highlighted areas), indicating a state of edit, labeling the artifact owner by username, and indicating user actions via real-time cursor positions (an existing Conceptboard feature). Artifacts in those areas should show whether they are "in-progress" and thus prevent concurrent changes by others 
(Maranzana, Segonds, Lesage, \& Nelson, 2012). Additional coordination cues could include integrated communication channels, such as chat, voice or video conferencing, as described in the following guideline.

\subsection{G2. Facilitate integrated multi-channel communication in the visual workspace}

The necessity for different modes of participation, as suggested by findings in the study, reflect a key polarity described by Wenger (Wenger et al., 2009), namely rhythm, through synchronous and asynchronous participation, or "togetherness and separation across time and space" (see Table 5). Likewise, typically synchronous features like chat can also be utilized asynchronously by serving as a searchable reference index.

In terms of synchronous interaction, screen-sharing and remote desktop features are considered crucial in providing synchronized screen views for distant collaborators, assisted through parallel audio/video input for better coordination. Having active speakers show up on the screen is also important, as it facilitates face-to-face "gaze awareness" (Ishii \& Kobayashi, 1992). Platforms or tools can thus support CoPs well in design-driven fields, through synchronous/asynchronous modes and various communication channels (chat, video, screen-sharing) directly integrated into the visual creative workspace.

\subsection{G3. Provide on-demand activity permissions}

This work found an insufficient range of user activity permissions. What we inferred is that distinct design phases are associated with different types of user behavior and interaction, especially in creativity workspaces (virtual canvas, vector-editing tools). For example, the final artistic design phases are largely individualistic. Synchronous collaboration at this phase can thus hinder, rather than enable, creative development processes. At the same time, less intrusive input, like suggestions and corrective comments from peers, as a sideactivity, may be beneficial in the prevention of errors in designing artifacts.

This calls for tools that provide authors with a choice of activity permissions for participants, for example view, edit, chat, add stickie, and point to. These could be either assigned to a specific workspace (i.e. canvas \#3), or a particular (labeled) artifact (i.e. interface menu) (see Table 6). Permissions could then bind to an index of user roles, to support specific access levels, as described in the following guideline.

\subsection{G4. Provide on-demand access roles}

This study revealed issues around intrusion, overwrites and duplication of design artifacts in CSTs. Additionally, different project phases required different levels of access, i.e. team-only or community-wide. To achieve this, additional tools had to be deployed, which increased the time and effort required. In response, with regards to G1, and in line with G3, we suggest that tools should provide on-demand administrator-defined user roles to reflect the member structure of the CoP.
Managed in conjunction with activity permissions (G3), these can aggregate a fluid, personalized, multi-level, multirole scheme, as the following table demonstrates:

For example, if a team member (owner) is working on a specific design artifact, s/he can assign a "View" permission for the Mentor and a "Chat" and "Voice Call" permission for Team Members 1 and 2, with the ability to change permissions at any point in the development process. Likewise, this could be applied by the administrator (i.e. the project manager) to larger areas such as an entire canvas. Settings should be easy to alter according to the needs of each project phase. In this way, the environment can serve as a single-user, team, community-wide or public space, bypassing the need to use additional tools.

\subsection{G5. Enable interoperability across CSTs, generic productivity and social networks}

Efficient participation requires community members who can work with spatially and conceptually proximal elements, be it design visuals, forum-posts, code files, calendars and so on. Managing a collection of unrelated tools can be overwhelming. Furthermore, members of the community do not tend to "live in" subject-specific tools such as distributed CSTs. Their day-to-day tools would instead typically include general productivity apps or SNs. As a result, using diverse tools in a CoP might compromise the availability and participation of its members.

Outcomes from this study show that CoP practice can significantly benefit from interoperable day-to-day environments (like SNs) and subject-specific tools (like CSTs). On a practical level, this synergy requires technical knowhow for the customization of APIs (Application Programming Interface) that allow applications to inter-connect, extending their functionality and access to common pools of data. Such efforts are becoming easier via new open standards utilizing W3C's Social Web Protocols ("W3C Launches for Social Web Application Interoperability," n.d.) or following initiatives like the data transfer project ("Data Transfer Project," n.d.). This project provides open-source code to enable seamless data portability (photos, mail, contacts, calendars, tasks) using publicly available APIs between platforms or service providers.

Adopting such technologies to configure CoPs can provide a unified experience similar to that of a consolidated platform: universal access, visibility of linked resources and communication facilities, and tailored tool functionality (i.e. CSTs.) via

Table 6. Proposed personalized use scheme: access roles and activity permissions index.

\begin{tabular}{lc}
\hline Activity permissions & Access roles \\
Workspace OR Artifact level & Workspace OR Artifact level \\
\hline$\square$ Edit & $\square$ Admin \\
$\square$ View & $\square$ Team \\
$\square$ Participate & $\square$ Team Leader \\
$\square$ Chat & $\square$ Member 1 (name) \\
$\square$ Stickies & $\square$ Member 2 (name) \\
$\square$ Voice Call & $\square$ Community \\
$\square$ Video Conference & $\square$ Mentor \\
$\square$ Screen Share & $\square$ Expert \\
$\square$ Point & $\square$ Client \\
$\square$ None & $\square$ Public \\
\hline
\end{tabular}


a single login and common navigation to ensure proximal and conceptual consistency and thus, enhanced participation.

\subsection{G6. Ensure collective design and understanding of CoP technology configuration}

Configuration decisions should be realized through participation of representative stakeholders in the community so that all activities, goals and limitations can be factored in (Goodyear \& Carvalho, 2016). Adequate time for training and familiarization should be allowed, especially in the case of diverse CoPs (i.e. cross-organizational), to ensure that all members have a clear understanding of how to utilize the configuration to its full potential.

The study's contribution is significant in that it reinforces existing VCoP heuristics (Wenger et al., 2009) through their application at the intersection of HE and industry, a critically important albeit under-investigated niche in modern pedagogy (Ivascu, Cirjaliu, \& Draghici, 2016; Scandura, 2016). More specifically:

a. While the CoP framework provides standardized strategies for the design and administration of communities (Wenger et al., 2009), this study offers empirical evidence of its enactment in the context of a formal HE curriculum. This study reports exhaustively on the actual process of a CoP steward identifying and mapping real community needs to the model's components (see section 3.4, step 1), following technology acquisition strategies (see section 3.4 , step 2) and making the final technology configuration decisions (see section 3.4, step 2a).

b. Further, the learners' technology-adoption findings have helped extract key guidelines provided in the form of detailed design heuristics, offering deeper insight into the design of similar ecologies and configurations (see guidelines G1 to G6).

c. The paper provides an augmented and tested guide for $\mathrm{CoP}$ administrators such as instructors, practitioners or researchers, who can benefit from targeted recommendations that are contextualized in the collaborative needs of design-heavy disciplines such as Media, Technology, HCI and Engineering (Dym et al., 2005).

As mentioned, research looking into the characteristics, structures and practices of CoPs within certain disciplines is lacking (Amin \& Roberts, 2008; Smith et al., 2017). We posit that this study provides the necessary degree of specificity to address the epistemic activities that are inherent to Design and related disciplines.

Additionally, while the VCoP framework (Wenger et al., 2009) serves as a guide for instructional designers, researchers and practitioners, research must be conducted into its empirical transfer and enactment. This work is in fact a validation of the technology configuration of a newly proposed crossorganizational CoP model. Other studies have yet to report on the implementation or adoption of similar configurations within the scope of CoPs (Pharo et al., 2014).

Furthermore, aside from providing general guidance, this study responds to ongoing calls to be "realistic about the kinds of knowledge that designers can use" (Carvalho \& Goodyear, 2014). By designers, we mean instructional designers or the people responsible for the design of learning. As it stands, more tangible, action-oriented forms of knowledge about CoP technology implementation (i.e. effective components thereof) can most benefit people who seek to adopt or customize such models to further enhance their learning environments.

\section{Conclusion}

This work looks at a specific area within the body of research on the design of VCoPs in HE. Specifically, this research focuses on an ecology and technology configuration that is localized in HE CoPs dealing with the disciplines of Design and other related fields, such as Engineering, Architecture, Technology and HCI. In examining a cross-organizational (academia/industry) $\mathrm{CoP}$, a relatively new and under-researched area, it reports on the design of technology configurations and investigates their type and level of adoption by particular members of the CoP, i.e. the learners. The findings have informed configuration guidelines to improve a) user awareness of activities and the visual artifacts in the shared space and through the course of time, $b$ ) the roles and activity permissions on both the artifact and the 'space' level and c) interoperability between subject-specific software (i.e. CSTs) and free, mainstream, generic productivity, social networking and communication tools to carry out CoP practices more effectively.

This study is limited in that it focuses exclusively on the design of a CoP configuration. Additionally, it should be mentioned that there are multiple dimensions in the investigation of cross-organizational CoPs, such as curriculum design, learning outcomes and social collaboration between CoP members. These are considered distinct, full-length research areas and are therefore presented in parallel studies. Finally, while the technology adoption outcomes perceived by learners are clearly the most critical part of our analysis, reporting on the perspectives of the rest of the members of the $\mathrm{CoP}$ would provide a broader spectrum of findings, a task that will be addressed in future work.

\section{Funding}

This work was supported by Horizon 2020739578

\section{ORCID}

Aekaterini Mavri (D) http://orcid.org/0000-0002-5076-5891 Andri Ioannou (D) http://orcid.org/0000-0002-3570-6578

Fernando Loizides (D) http://orcid.org/0000-0003-0531-6760

\section{References}

Abras, C., Maloney-Krichmar, D., \& Preece, J. (2004). User-centered design. Bainbridge, W. Encyclopedia of Human-Computer Interaction. Thousand Oaks: Sage Publications, 37(4), 445-456.

Adobe Dreamweaver (Version 12). (2012). Adobe systems.

Albats, E. (2018). Facilitating university-industry collaboration with a multilevel stakeholder perspective (Research Series Number 798). Acta Universitatis Lappeenrantaensis. 
Amin, A., \& Roberts, J. (2008). Knowing in action: Beyond communities of practice. Research Policy, 37(2), 353-369. doi:10.1016/j. respol.2007.11.003

Baek, E.-O., Cagiltay, K., Boling, E., \& Frick, T. (2008). User-centered design and development. Handbook of Research on Educational Communications and Technology, 1, 660-668.

Behance. (n.d.). Retrieved from https://www.behance.net/

Bhatnagar, T., \& Badke-Schaub, P. (2017). Design thinking and creative problem solving for undergraduate engineering education in India: The need and relevance. International Conference on Research into Design (pp. 953-967). India: Springer.

Bloor, M. (2001). Focus groups in social research. Great Britain: Sage.

Boylan, M. (2010). Ecologies of participation in school classrooms. Teaching and Teacher Education, 26(1), 61-70. doi:10.1016/j. tate.2009.08.005

Braun, V., Clarke, V., Hayfield, N., \& Terry, G. (2019). Thematic Analysis. In P. Liamputtong (Ed.), Handbook of research methods in health social sciences (pp. 843-860). doi:10.1007/978-981-10-52514_103

Brown, J. S., Collins, A., \& Duguid, P. (1989). Situated cognition and the culture of learning. Educational Researcher, 18(1), 32-42. doi:10.2307/ 1176008

Brown, P. (2015). Communities of practice: A heuristic for workplace reflection in higher education. Rapport: the International Journal for Recording Achievement, Planning and Portfolios, 1, 180-197.

Buy Adobe Illustrator CC | Vector graphic design software. (n.d.). Retrieved from https://www.adobe.com/cy_en/products/illustrator.html

Buy Adobe Photoshop CC | Best photo, image, and design editing software. (n.d.). Retrieved from https://www.adobe.com/cy_en/products/ photoshop.html

Carvalho, L., \& Goodyear, P. (2014). Framing the analysis of learning network architectures. In L. Carvalho \& P. Goodyear (Eds.), The architecture of productive learning networks (pp. 66-88). Routledge.

Cherry, E., \& Latulipe, C. (2014). Quantifying the creativity support of digital tools through the creativity support index. ACM Transactions on Computer-Human Interaction (TOCHI), 21(4), 21. doi:10.1145/ 2617588

Chi, M. T. (1997). Quantifying qualitative analyses of verbal data: A practical guide. The Journal of the Learning Sciences, 6(3), 271-315. doi:10.1207/s15327809j1s0603_1

Clarke, L. (2009). The POD model: Using communities of practice theory to conceptualise student teachers' professional learning online. Computers \& Education, 52(3), 521-529. doi:10.1016/j. compedu.2008.10.006

Conceptboard Virtual Collaboration Workplace for Teams. (n.d.). Retrieved from https://conceptboard.com/

Conte, T., Massollar, J., Mendes, E., \& Travassos, G. H. (2007). Usability evaluation based on web design perspectives. First International Symposium on Empirical Software Engineering and Measurement (ESEM 2007) (pp. 146-155). doi:10.1109/ESEM.2007.30

Crossouard, B., \& Pryor, J. (2008). Becoming researchers: A sociocultural perspective on assessment, learning and the construction of identity in a professional doctorate. Pedagogy, Culture \& Society, 16(3), 221-237. doi:10.1080/14681360802346614

Data Transfer Project. (n.d.). Retrieved from https://datatransferproject. dev

Davis, F. D., Bagozzi, R. P., \& Warshaw, P. R. (1989). User acceptance of computer technology: A comparison of two theoretical models. Management Science, 35(8), 982-1003. doi:10.1287/mnsc.35.8.982

deChambeau, A. (2017). The practice of being a student: CoPs and graduate student success. Implementing Communities of Practice in Higher Education: Dreamers and Schemers, 395-422.

Dolmans, D., Michaelsen, L., Van Merrienboer, J., \& van der Vleuten, C. (2015). Should we choose between problem-based learning and team-based learning? No, combine the best of both worlds! Medical Teacher, 37(4), 354-359. doi:10.3109/0142159X.2014.948828

Duch, B. J., Groh, S. E., \& Allen, D. E. (2001). The power of problembased learning: A practical" how to" for teaching undergraduate courses in any discipline. USA: Stylus Publishing, LLC.
Dym, C. L., Agogino, A., Eris, O., Frey, D., \& Leifer, L. (2005). Engineering design thinking, teaching, and learning. Journal of Engineering Education Washington, 94, 103-120. doi:10.1002/j.21689830.2005.tb00832.x

Eggleton, K., Fortier, R., Fishman, T., Hawken, S. J., \& Goodyear-Smith, F. (2019). Legitimate participation of medical students in community attachments. Education for Primary Care, 30(1), 35-40. doi:10.1080/ 14739879.2018.1563503

Forghani, A., Venolia, G., \& Inkpen, K. (2014). Media2gether: Sharing media during a call. Proceedings of the 18th International Conference on Supporting Group Work (pp. 142-151). Sanibel Island, FL: ACM.

G Suite: Collaboration \& Productivity Apps for Business. (n.d.). Retrieved from https://gsuite.google.com/

Gabriel, A., Monticolo, D., Camargo, M., \& Bourgault, M. (2016). Creativity support systems: A systematic mapping study. Thinking Skills and Creativity, 21, 109-122. doi:10.1016/j.tsc.2016.05.009

Goodyear, P., \& Carvalho, L. (2016). Activity centred analysis and design in the evolution of learning networks. Tenth International Conference on Networked Learning. UK: Lancaster University Lancaster.

Google Drive Cloud Storage \& File Backup for Photos, Docs \& More. (n. d.). Retrieved from www.google.com/drive/

Gunawardena, C. N., Hermans, M. B., Sanchez, D., Richmond, C., Bohley, M., \& Tuttle, R. (2009). A theoretical framework for building online communities of practice with social networking tools. Educational Media International, 46(1), 3-16. doi:10.1080/09523980802588626

Gutwin, C., Greenberg, S., \& Roseman, M. (1996). Workspace awareness in real-time distributed groupware: Framework, widgets, and evaluation. In People and computers XI (pp. 281-298). Springer.

Hafeez, K., Alghatas, F. M., Foroudi, P., Nguyen, B., \& Gupta, S. (2019). Knowledge sharing by entrepreneurs in a virtual community of practice (VCoP). Information Technology \& People, 32(2), 405-429. doi:10.1108/ITP-09-2016-0202

Herrington, J., Reeves, T. C., \& Oliver, R. (2014). Authentic learning environments. In J. M. Spector, M. D. Merrill, J. Elen, \& M. J. Bishop (Eds.), Handbook of research on educational communications and technology (pp. 401-412). Springer.

Huang, H.-C., \& Perng, Y.-H. (2017). Factors influencing the success of communities of practice in the interior decoration industry. 2017 International Conference on Organizational Innovation (ICOI 2017). Netherlands: Atlantis Press.

Hypothesis - The Internet, peer reviewed. (n.d.). Retrieved from https:// web.hypothes.is/

Ishii, H., \& Kobayashi, M. (1992). ClearBoard: A seamless medium for shared drawing and conversation with eye contact. Proceedings of the SIGCHI Conference on Human Factors in Computing Systems - CHI '92 (pp. 525-532). doi:10.1145/142750.142977

Iskanius, P., \& Pohjola, I. (2016). Leveraging communities of practice in university-industry collaboration: A case study on Arctic research. International Journal of Business Innovation and Research, 10(2-3), 283-299. doi:10.1504/IJBIR.2016.074830

Ivascu, L., Cirjaliu, B., \& Draghici, A. (2016). Business model for the university-industry collaboration in open innovation. Procedia Economics and Finance, 39, 674-678. doi:10.1016/S2212-5671(16)30288-X

Jeffs, L., McShane, J., Flintoft, V., White, P., Indar, A., Maione, M., ... Scavuzzo, L. (2016). Contextualizing learning to improve care using collaborative communities of practices. BMC Health Services Research, 16(1), 464. doi:10.1186/s12913-016-1566-4

Johnston, D. H. (2016). 'Sitting alone in the staffroom contemplating my future': Communities of practice, legitimate peripheral participation and student teachers' experiences of problematic school placements as guests. Cambridge Journal of Education, 46(4), 533-551. doi:10.1080/ 0305764X.2015.1069793

Khalid, M. S., \& Strange, M. H. (2016). School teacher professional development in online communities of practice: A systematic literature review. ECEL 2016: 15th European Conference on e-LearningEuropean Conference on e-Learning (pp. 605-614). Prague, Czech Republic: Academic Conferences and Publishing International.

Lave, J., \& Wenger, E. (1991). Situated learning: Legitimate peripheral participation. USA: Cambridge University Press. 
Lave, J., \& Wenger, E. (1999). Legitimate peripheral participation. In P. Murphy (Ed.), Learners, learning and assessment (pp. 83-89). London, UK: The Open University.

Lazar, J., Preece, J., Gasen, J., Winograd, T., \& Winograd, T. (2002). New issues in teaching HCI: Pinning a tail on a moving donkey. CHI'02 Extended Abstracts on Human Factors in Computing Systems (pp. 696-697). Minneapolis, MN: ACM.

Lombardi, M. M. (2007). Authentic learning for the 21st century: An overview. Educause Learning Initiative, 1(2007), 1-12.

Lowdermilk, T. (2013). User-centered design: A developer's guide to building user-friendly applications. USA: O'Reilly Media, Inc.

Lowe, D., \& Eklund, J. (2002). Client needs and the design process in web projects. Journal of Web Engineering, 1(1), 23-36.

Maranzana, N., Segonds, F., Lesage, F., \& Nelson, J. (2012). Collaborative design tools: A comparison between free software and PLM solutions in engineering education. In L. Rivest, A. Bouras, \& B. Louhichi (Eds.), Product lifecycle management. towards knowledge-rich enterprises (Vol. 388., pp. 547-558). doi:10.1007/978-3-642-35758-9_49

Maxwell, J. A. (2012). Qualitative research design: An interactive approach (Vol. 41). USA: Sage publications.

McLoughlin, C., Patel, K. D., O'Callaghan, T., \& Reeves, S. (2018). The use of virtual communities of practice to improve interprofessional collaboration and education: Findings from an integrated review. Journal of Interprofessional Care, 32(2), 136-142. doi:10.1080/ 13561820.2018.1433135

Moodle Open-source learning platform | Moodle.org. (n.d.). Retrieved from https://moodle.org/

Morton, J. (2012). Communities of practice in higher education: A challenge from the discipline of architecture. Linguistics and Education, 23(1), 100-111. doi:10.1016/j.linged.2011.04.002

Mulgan, G., Townsley, O., \& Price, A. (2016). The challenge-driven university: How real-life problems can fuel learning. In Nesta.

Nguyen, V., Dang, H. H., Do, N.-K., \& Tran, D.-T. (2016). Enhancing team collaboration through integrating social interactions in a Web-based development environment. Computer Applications in Engineering Education, 24(4), 529-545. doi:10.1002/cae.v24.4

Norman, D. A. (1986). Cognitive engineering. User Centered System Design, 31, 61.

Norman, D. A. (1999). Affordance, conventions, and design. Interactions, 6(3), 38-43. doi:10.1145/301153.301168

Pattinson, S., \& Preece, D. (2014). Communities of practice, knowledge acquisition and innovation: A case study of science-based SMEs. Journal of Knowledge Management, 18(1), 107-120. doi:10.1108/ JKM-05-2013-0168

Patton, M. Q. (1980). Qualitative research and evaluation methods. In Book qualitative research and evaluation methods. Thousand Oaks, CA: Sage Publications.

Pharo, E., Davison, A., McGregor, H., Warr, K., \& Brown, P. (2014). Using communities of practice to enhance interdisciplinary teaching: Lessons from four Australian institutions. Higher Education Research \& Development, 33(2), 341-354. doi:10.1080/07294360.2013.832168

Poole, M. S., \& Holmes, M. E. (1995). Decision development in computer-assisted group decision making. Human Communication Research, 22(1), 90-127. doi:10.1111/hcre.1995.22.issue-1

Prototypes, Specifications, and Diagrams in One Tool | Axure Software. (n.d.). Retrieved from https://www.axure.com/

Rauniar, R., Rawski, G., Yang, J., \& Johnson, B. (2014). Technology acceptance model (TAM) and social media usage: An empirical study on Facebook. Journal of Enterprise Information Management, 27(1), 6-30. doi:10.1108/JEIM-04-2012-0011

Renaud, K., \& Van Biljon, J. (2008). Predicting technology acceptance and adoption by the elderly: A qualitative study. Proceedings of the 2008 Annual Research Conference of the South African Institute of Computer Scientists and Information Technologists on IT Research in Developing Countries: Riding the Wave of Technology (pp. 210-219). New York, NY: ACM.

Rourke, A., \& Mendelssohn, J. (2017). Facilitating a Community of Practice $(\mathrm{CoP})$ in the arts: Connecting online university learning to 'real-world'Experience. In J. McDonald \& A. Cater-Steel (Eds.), Implementing communities of practice in higher education (pp. 475-499). Springer.
Saldaña, J. (2015). The coding manual for qualitative researchers. USA: Arizona State University.

Savery, J. R. (2015). Overview of problem-based learning: Definitions and distinctions. Essential Readings in Problem-Based Learning: Exploring and Extending the Legacy of Howard S. Barrows, 9, 5-15.

Scandura, A. (2016). University-Industry collaboration and firms' R\&D effort. Research Policy, 45(9), 1907-1922. doi:10.1016/j.respol.2016.06.009

Shneiderman, B. (2000). Creating creativity: User interfaces for supporting innovation. ACM Transactions on Computer-Human Interaction (TOCHI), 7(1), 114-138. doi:10.1145/344949.345077

Smith, S. U., Hayes, S., \& Shea, P. (2017). A critical review of the use of Wenger's Community of Practice (CoP) theoretical framework in online and blended learning research, 2000-2014. Online Learning, 21(1), 209-237. doi:10.24059/olj.v21i1.963

Spagnoletti, P., Resca, A., \& Lee, G. (2015). A design theory for digital platforms supporting online communities: A multiple case study. Journal of Information Technology, 30(4), 364-380. doi:10.1057/jit.2014.37

Stone, S., Doyle, P., Donlon, E., Gormley, C., Walsh, E., O'Keeffe, N., ... Ferguson, P. B. (2017). Meitheal: An Irish case study in building a virtual community of practice in transitional times. In J. McDonald (Ed.), Implementing communities of practice in higher education (pp. 449-474). Australia: Springer.

Tseng, F.-C., \& Kuo, F.-Y. (2014). A study of social participation and knowledge sharing in the teachers' online professional community of practice. Computers \& Education, 72, 37-47. doi:10.1016/j.compedu.2013.10.005

Venkatesh, V., Morris, M. G., Davis, G. B., \& Davis, F. D. (2003). User acceptance of information technology: Toward a unified view. MIS Quarterly, 27, 425-478. doi:10.2307/30036540

Vredenburg, K., Mao, J.-Y., Smith, P. W., \& Carey, T. (2002). A survey of user-centered design practice. Proceedings of the SIGCHI Conference on Human Factors in Computing Systems (pp. 471-478). Minneapolis, MN: ACM.

W3C Launches for Social Web Application Interoperability. (n.d.). Retrieved from https://www.w3.org/2014/06/social.html.en

Wenger, E. (1998). Communities of practice: Learning, meaning, and identity. New York, NY: Cambridge University Press.

Wenger, E., McDermott, R. A., \& Snyder, W. (2002). Cultivating communities of practice: A guide to managing knowledge. Boston, MA: Harvard Business Press.

Wenger, E., White, N., \& Smith, J. D. (2009). Digital habitats: Stewarding technology for communities. Portland, OR: CPsquare.

Wikipedia contributors. (2018). Apache subversion - Wikipedia, the free encyclopedia. Retrieved from https://en.wikipedia.org/w/index. php?title=Apache_Subversion\&oldid $=86949325$

\section{About the Authors}

Aekaterini Mavri is a $\mathrm{PhD}$ candidate and a full-time member of the special teaching staff at the Department of Multimedia and Graphic Arts at the Cyprus University of Technology. Her research focusses on the role of cross-organizational Communities of Practice on learning in the Design and relevant fields in Higher Education.

Andri loannou is an Assistant Professor at the Department of Multimedia and Graphic Arts and Head of the Cyprus Interaction Lab at the Cyprus University of Technology. She is also the Leader of the Interactive Media and Education/Edutainment research group at the Research Center on Interactive Media, Smart Systems and Emerging Technologies (RISE). In her work, she aims to understand the significant supportive and mediating role of technology in promoting learning, communication \& collaboration, and social change in varied circumstances and contexts.

Fernando Loizides is a Lecturer (Assistant Prof.) in Computer Science and Informatics at Cardiff University. Fernando's main area of research lies in Information Interaction, HCI and Digital Libraries and Accessibility. He has a computer science background, which he combines with digital library research to investigate how systems can be enhanced by emerging technologies. He has extensive experience in user testing and project management, both within industry and academia. 